\title{
Study for the Key Success Factors of Female Direct Selling Business
}

\author{
Fang Shin Lin
}

Feng Chia University

E-mail address antifatorg@gmail.com

\begin{abstract}
The purpose of this study is to understand the key factors which result in the success of female direct selling businesses. Investigate the reasons why women support most of their performance in the direct selling industry. According to the Taiwan Fair Trade Commission's 2018 direct selling industry survey report, the total direct selling of Taiwan in 2018 was 83.027 billion NTD, with a total of 3.0838 million distributors. There were 2.158 million female distributors, accounting for 3.083 million total distributors. It is a proportion of 69.99 percentage points, an increase of 1.67 percentage points compared with 2017. This proportion is also comparable to $74 \%$ of global distributors is female, calculated by the World Federation of Direct Selling Associations(WDSFA)! The number of female distributors is more than twice that of men. The proportion is getting higher and higher! In the literature review, issues such as "female enterpriser" related literature and "gender roles" and "personality traits," "erotic capital" in the "direct selling industry" have been used as the main resource axis for collecting relevant domestic and foreign literature. Based on the literature summary and the expression of the expert's intention, the expert questionnaire will be based on the professors and the female distributors who have been in the top direct selling companies in Taiwan for more than two years in 2018 to find indicators of success factors, and then use the Analytic Hierarchy Process Method (AHP) Design a general questionnaire. The general questionnaire is for the distributors in Taiwan. Expected to recover 100 copies in the web questionnaire, After obtaining the resources, it will be processed and analyzed. The research results show that the influence facets and factors may have: Female Entrepreneur, Gender roles, Personality Traits, and direct selling business. In particular, the female gender role play and erotic capital may have a greater impact on the results of operating the direct selling business. The study includes the following topics are understanding the background of the female direct selling entrepreneurs, explain the challenges and difficulties of female direct selling entrepreneurs, relevant resources related to female direct selling entrepreneurs and research on the key success factors of female direct selling business.Today, female entrepreneurs are very hard and required to play multiple roles. Between family and business, how do female entrepreneurs make a good performance? I hoped that through this study, key factors could be identified in order to minimize entrepreneurial risks and allocate resources effectively.
\end{abstract}

Keywords: female entrepreneur, gender role, personality traits, erotic capital, direct selling business 


\section{INTRODUCTION}

In the business model, since the introduction of direct sales, it has provided people with a small business entrepreneurial model, especially for women's income. It is very important, but not every participant can get benefits. This research starts with the data released by the government. Analyze and explore the advantages of women in this industry.

According to the Taiwan Fair Trade Commission's 2018 direct selling industry survey report, the total direct selling of Taiwan in 2018 was 83.027 billion NTD, with a total of 3.0838 million distributors.

There were 2.158 million female distributors, accounting for 3.083 million total distributors. It is a proportion of 69.99 percentage points, an increase of 1.67 percentage points compared with 2017.

This proportion is also comparable to $74 \%$ of global distributors is female, calculated by the World Federation of Direct Selling Associations(WDSFA)!

The number of female distributors is more than twice that of men. The proportion is getting higher and higher!

\section{LITERATURE REVIEW}

After considering the nature of the work of direct selling and the characteristics of women, the following results were obtained by consulting various documents to find out the relevant elements that affect women's direct selling work.

In the literature review, issues such as "female entrepreneur" related literature and "gender roles" and "personality traits," "erotic capital" in the "direct selling industry" have been used as the main resource axis for collecting relevant domestic and foreign literature (Visa / Logica Research, 2018; Browne, Moylan, \& Scaife, 2004; Kao, Cheng-Shu,1999; Healthline,2020; Philip Thomas Udo-Imeh, 2015;Lykourentzou, Antoniou, Naudet \& Dow, 2016; Shepherd, 1993; WFDSA, 2018; Taiwan Multilevel MLM Management Law, 2014; China Direct Sales Regulations, 2005; Lin Jinnan, 2017; Direct Selling Century, 2019; Alison Wolf 2015; Catherine Hakim 2012; Shalini Unnikrishnan, Roy Hanna2019).

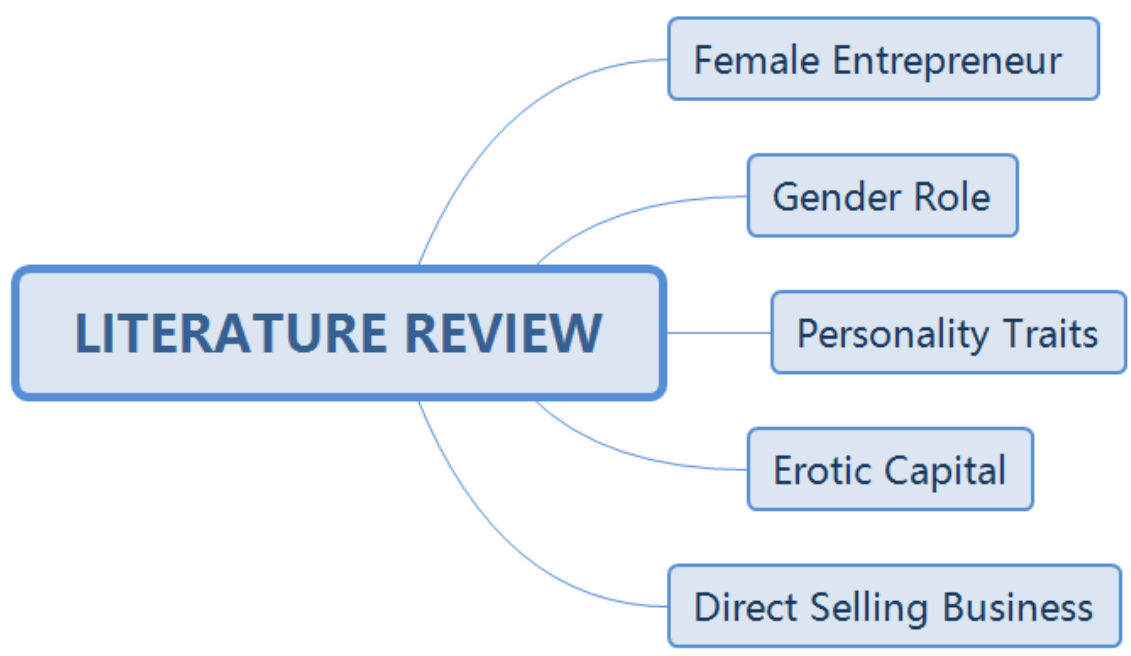

Fig. 1 The literature review focus on the 5 Facets. 


\section{Female Entrepreneur}

\section{Let dream come true}

Improve living standards

To get rich opportunities

Debt repayment

Taking care of family and work together

Family support

personal interest

Insufficient venture capital

Fig. 2. Facet 1: female entrepreneur/8 factors from the literature review

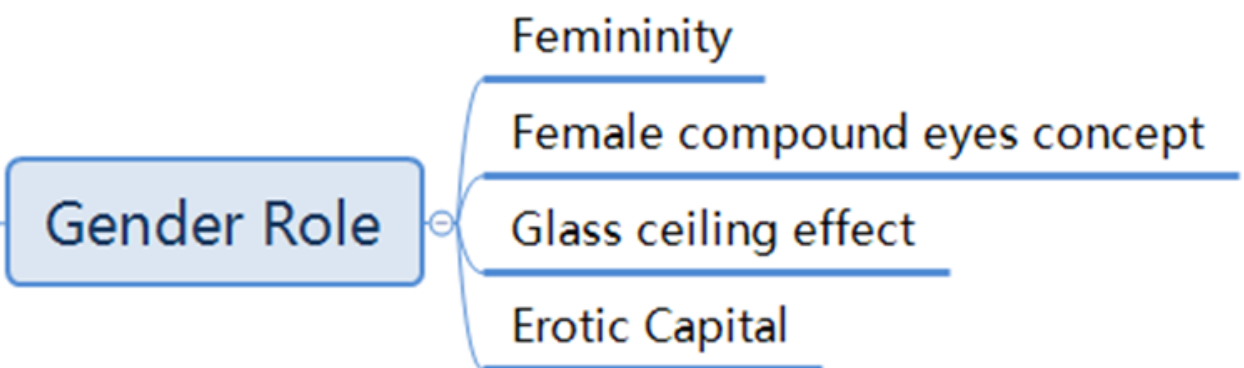

Fig. 3. Facet 2: gender role $/ 4$ factors from the literature review

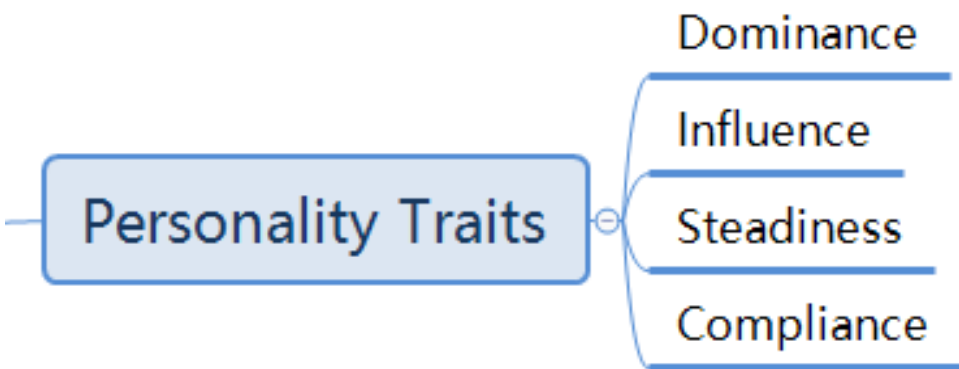

Fig. 4. Facet 3: personality traits $/ 4$ factors from the literature review 


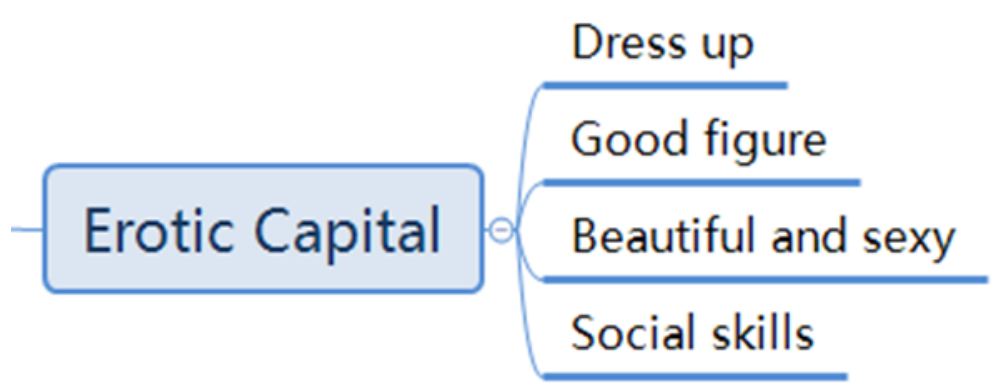

Fig. 5. Facet 4: Erotic Capital /4 factors from the literature review

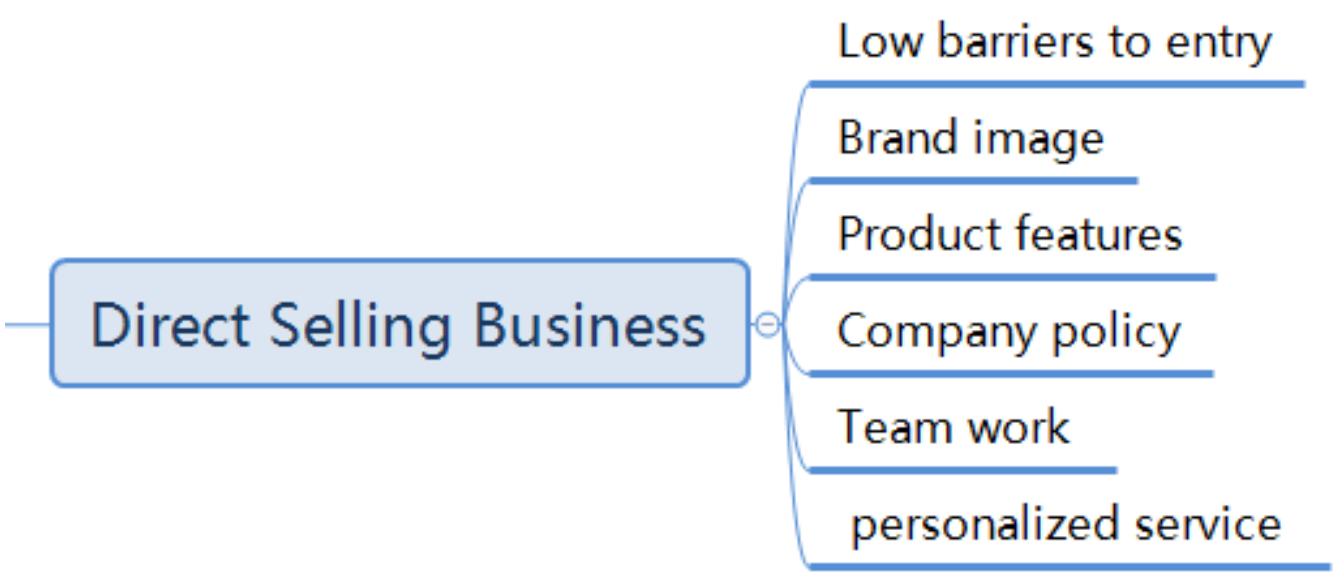

Fig. 6. Facet 5: Direct selling Business /6 factors from the literature review

\section{RESEARCH METHODOLOGY}

\section{Research structure}

This research adopts the stage method to advance through the integration of relevant domestic and foreign literature. In the first stage, from the literature discussion, the key success factors of direct selling entrepreneurship are selected, and after discussion with the instructor, the prototype of the research structure and the preliminary content of the questionnaire are proposed. Second, experts are entrusted with reviewing the questionnaire content to determine whether the content can fully express the research Purpose and scope. At this stage, the Lawshe test is used to assess the content validity of each aspect and change.

In the second stage, based on the expert verification results and suggestions, a revised research dimension is generated, and general questionnaires are designed accordingly. In this stage, the Analytic Hierarchy Process Method (AHP) is used to design general questionnaires, using Expertchoice 2000 and Matlab, etc. As a resource management and analysis tool, the software detects the importance of various factors. 


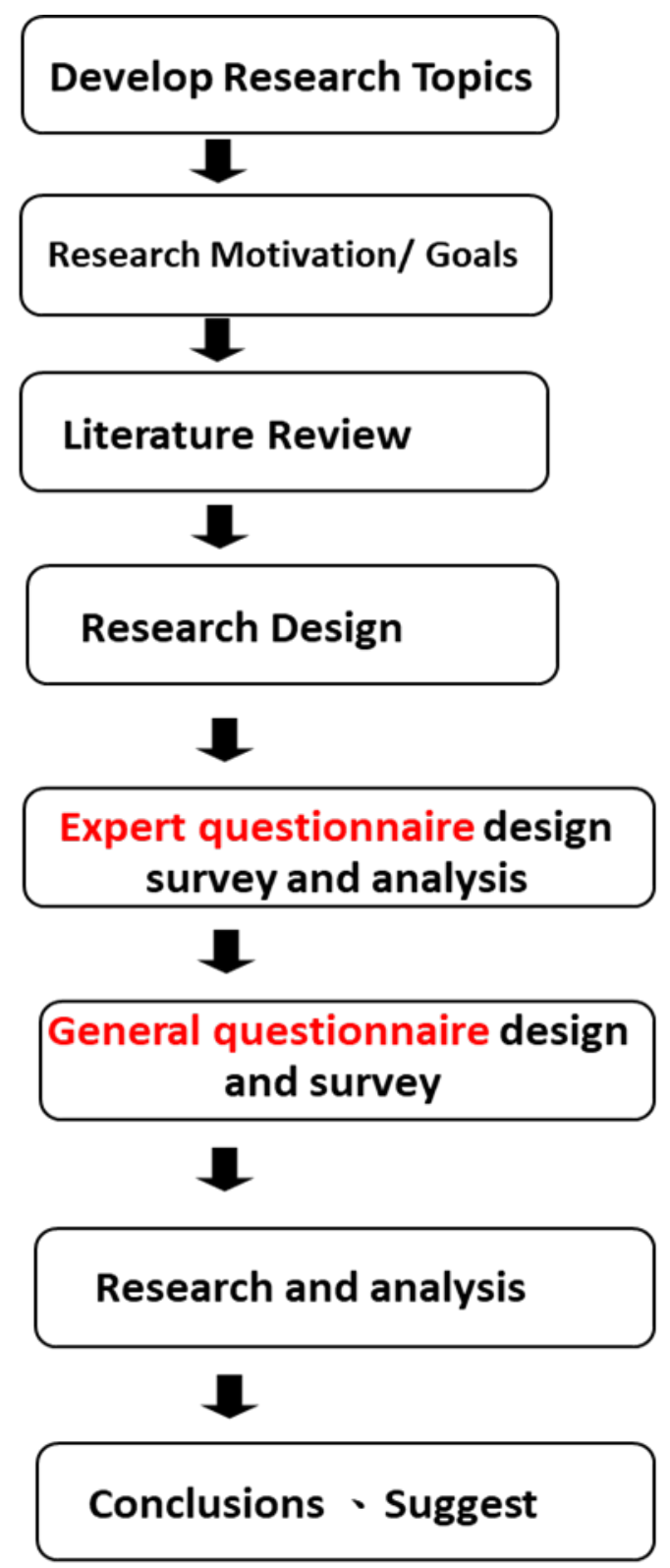

Fig. 7: Research architecture

\section{Explanation of each research stage} Business

Develop the research Subject: Study for the Key Success Factors of Female Direct Selling

Research Motivation: Taiwan Fair Trade Commission's 2018 direct selling industry survey report

Research Design: Design expert questionnaires and interview experts as a facet to establish critical success factors. 
Analytic Hierarchy Process Method(AHP): designing a general questionnaire as a key success factor to explore in order to make the research conclusions more meaningful. Related success factors for women supporting direct selling

Conclusion: Provide a reference for the direct selling industry and marketing industry $\sim$ Development strategy and advice and resource allocation and investment!

\section{Expert Questionnaire}

Based on the literature summary and the expression of the expert's intention, the expert questionnaire will be based on the professors and the female distributors who have been in the top direct selling companies in Taiwan for more than two years in 2018 to find indicators of success factors, and then use the Analytic Hierarchy Process Method (AHP) Design a general questionnaire.

The general questionnaire is for the distributors in Taiwan. She is expected to recover 100 copies of the web questionnaire.

\section{Expert Background Resources}

A total of 36 people participated in this expert questionnaire, including direct sellers, academics, and the business field.

\section{Expert Background Resources}

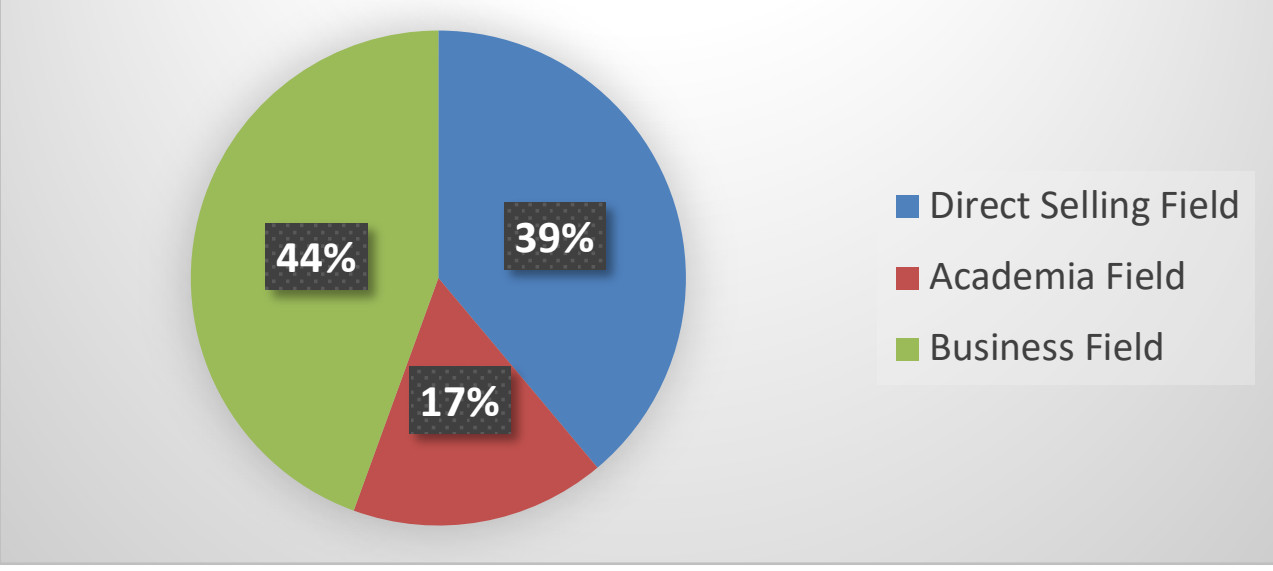

Fig. 8: Expert Background Resources

Based on the Expert Questionnaire, this study may find some indicators of success factors:

This study uses the average questionnaire calculation based on the results of the expert questionnaire. Since the expert questionnaire has five scales, the Ne values of "Very Important" and "Important" are set to 1, and " The Ne values of "Normal," "Unimportant" and "Very Unimportant" are set to 0 , and then the CVR value is calculated according to the Lawshe calculation method. If the CVR result is greater than or equal to 0.31 , this factor is used. Otherwise, it is less than the CVR value of 0.31 ; this factor is eliminated.

Content Validity Ratio (CVR)

$\mathrm{CVR}=(\mathrm{Ne}-\mathrm{N} / 2) \div(\mathrm{N} / 2)$

$\mathrm{Ne}$ : Determine the factor as a necessary expert order;

$\mathrm{N}$ : Experts number 
The significant level it provides, the CVR value of each factor, is tested at a significant level of 0.05 .

CVR expert number and standard value requirements:

Expert number 36

Required CVR 0.31

Thirty-six experts were selected as the basis for this study. Therefore, the value of CVR in this study must be greater than or equal to 0.31 in order to continue the subsequent measurement in the facet.

Source: Lawshe (1975), significant level $=0.05$

\section{FINDING AND DISCUSSION}

Based on the Expert Questionnaire, there are 5 Facets, and 20 factors are eliminated for the Key Success Factors of Female Direct Selling Business.

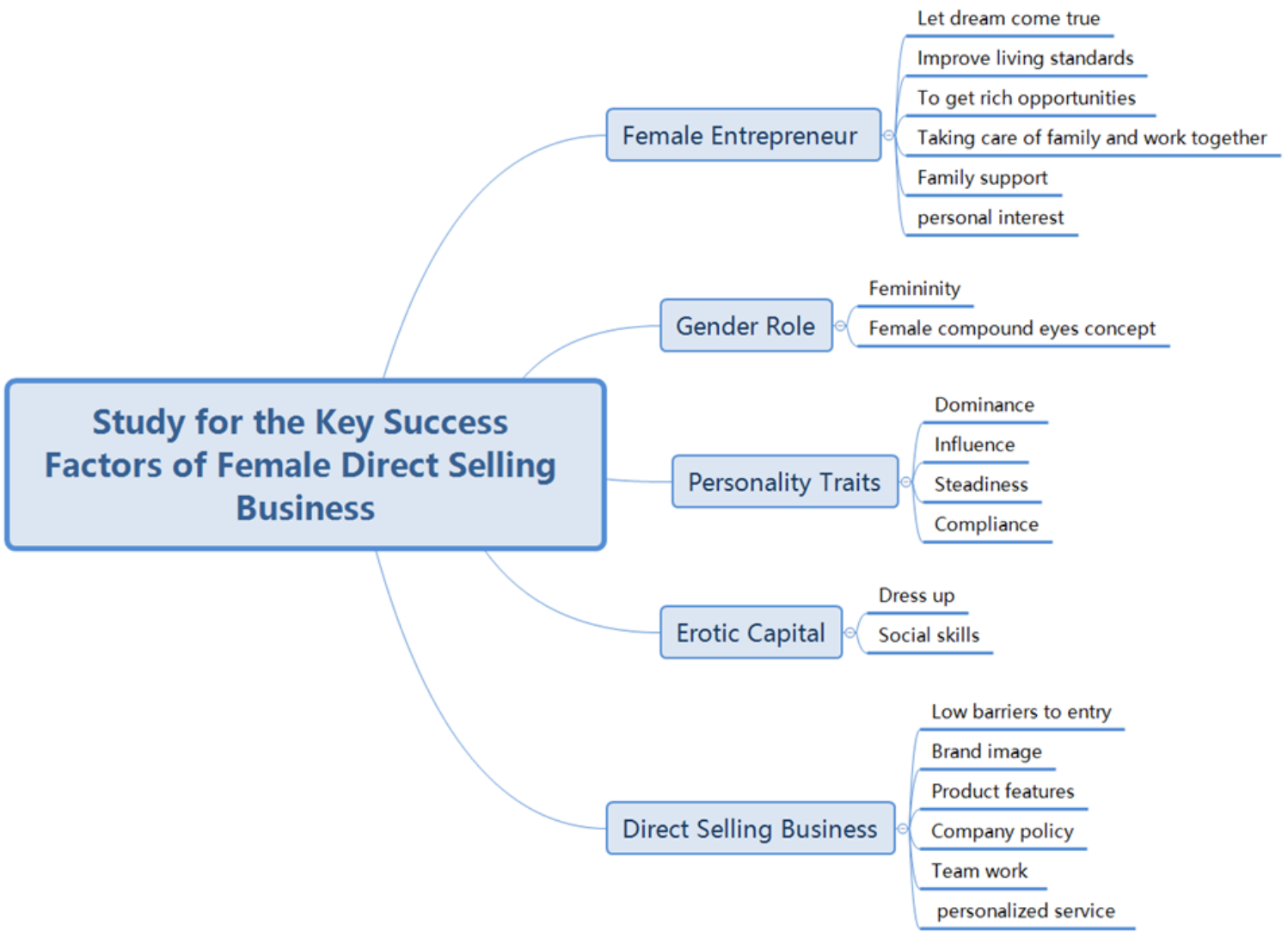

Fig. 9. the Key Success Factors of Female Direct Selling Business:5 Facets/20 factors is eliminated

There are five factors that are not valid and are excluded, include:

1. Female Entrepreneur / Debt repayment and Insufficient venture capital

2. Gender Role/Glass ceiling effect

3. Erotic Capital/Good figure and Beautiful and sexy

The reasons for women's success in the direct selling industry are not affected by financial problems and physical beauty. It's different from the common feeling of ordinary people. 


\section{CONCLUSION AND FURTHER RESEARCH}

This is a part of the series of studies about Direct Selling Business.

Research is ongoing. Through the research at this stage, we have obtained 20 key success factors that are helpful for women to engage in direct selling business operations and provide the application of human resources in the organization and marketing industry.

Next steps and future research:

After this research, we can continue to do two research phases to achieve an in-depth discussion of the importance of key factors about Female Direct Selling Business.

1.General questionnaire

Use the Analytic Hierarchy Process Method (AHP) Design a general questionnaire for the 20 factors. The general questionnaire is for the distributors in Taiwan to recover 100 copies in the web questionnaire.

Expect the following results:

A. Sort all factor weights in the Key Success Factors of Female Direct Selling Business.

B. Comparison of the distributors in different basic background and views on the key factors.

C. The relative importance of each key success factor.

2.Qualitative research:

The last research is qualitative interviews with 15 senior direct-selling workers, in-depth discussion on whether the above matches and possible reasons.

Provide the useful application of human resources in the Direct Selling Business and marketing industry.

In particular, how to make the development of the industry more helpful in the application of women's power, and at the same time, let women choose efficient efforts at work.

\section{REFERENCES}

Alison Wolf ( 2015), THE XX FACTOR: How the Rise of Working Women Has Created a Far Less Equal World.

Browne, J., Moylan, T., \& Scaife, A. (2004). Female entrepreneurs-out of the frying pan into the fire. Paper presented at the 27th ISBA Conference.

Catherine Hakim (2012). Honey Money: The Power of Erotic Capital. UK: Penguin.

Direct Selling Century (2019). Embrace her power. Taipei: Chuanzhi International Culture.

Healthline (2020). What is the glass ceiling theory and effect ?. Retrieved June 16, 2020, from https://www.healthline.com/health/mental-health/glass-ceiling-effect\#how-widespread-isthe-glass-ceiling.

Kao, Cheng-Shu, 1999, Boss's Wife: The Economic Activities and Social Significance of Taiwan's Small and Medium-sized Enterprise "Boss's Wife," Taipei: Lianjing.

Lin Jin-nan (2017). Basic information about the direct selling industry. Taipei: Taiwan Industry Economics Services.

Lykourentzou, A. Antoniou, Y. Naudet, and S. P. Dow (2016). Personality matters: Balancing for personality types leads to better outcomes for crowd teams, the 19th ACM Conference on Computer-Supported Cooperative Work \& Social Computing, pp. 260-273.

Philip Thomas Udo-Imeh (2015). Influence of Personality on the Buying Behaviour of Undergraduate Students in Universities in Cross River State, Nigeria, International Journal of Marketing Studies, Vol. 7, No. 4 (2015). 
Shalini Unnikrishnan and Roy Hanna (2019).The Trillion-Dollar Opportunity in Supporting Female Entrepreneurs by Shalini Unnikrishnan and Roy Hanna, Harvard Business Review, October 31, 2019.

Shepherd (1993). Building a Discipline of Communication, Journal of Communication, September 1993.

Visa/Logica Research (2019). Business Wire. Retrieved January 30, 2019, from https://www.businesswire.com/news/home/20190130005634/en/

WFDSA (2018). WFDSA Reports Record 2018. Retrieved June 18, 2019, from https://www.directsellingnews.com/wfdsa-reports-record-2018/ 